\section{References}

1 Boey ML, Colaco CB, Gharavi AE, Elkon KB, Loizou S, Hughes GRV. Thrombosis in systemic lupus erythematosus: striking association with the presence of circulating lupus anticoagulant. Br Med J 1983;287:1021-3.

2 Exner T, Rickard KA, Kronenberg H. Studies on phospholipids in the actions of a lupus coagulation inhibitor. Pathology 1975;7:319-28.

${ }^{3}$ Carreras LO, Defreyn G, Machin SJ, et al. Arterial thrombosis, intrauterine death and the "lupus" anticoagulant detection of immunoglobin interfering with prostacyclin formation. Lancet $1981 ; \mathrm{i}: 244$.
4 Shapiro SS, Thiagarajan P. Lupus anticoagulants. Prog Hemost Thromb 1982;6:263-85.

${ }^{5}$ Mazen E, Amiram E. Thromboembolism in patients with the 'lupus'-type, circulating anticoagulant. Arch Intern Med 1984;144:510-15.

${ }^{6}$ Lubbe WF, Palmar SJ, Butler WS, Laggins GC. Fetal survival after prednisolone suppression of maternal lupus anticoagulant. Lancet 1983; i:1361-3.

Correspondence to Dr S Appan, Department of Paediatrics, Singapore General Hospital, Outram Road, Singapore 0316.

Received 5 January 1987

\title{
Swivel walkers in Duchenne muscular dystrophy
}

\author{
J R SIBERT, V WILLIAMS, R BURKINSHAW, AND S SIBERT
}

Llandough Hospital, Penarth, South Glamorgan, University Hospital of Wales, Cardiff, and Pentwyn School, Cardiff, Wales

SUMMARY Swivel walkers were used to provide low energy ambulation in 11 boys with Duchenne muscular dystrophy in schools for the physically handicapped in South Glamorgan. Our preliminary experience suggests that these walkers improve the quality of life and provide a useful part of the physical treatment of the condition.

There are clear advantages in prolonging the mobilisation of boys with Duchenne muscular dystrophy, most particuarly in improving morale. The use of long leg calipers was first advocated by Spencer and Vignos in the United States ${ }^{1}$ and has been used in the United Kingdom, particularly at the Hammersmith Hospital. ${ }^{2}$ Nevertheless, this approach has not been universally accepted. There have been difficulties with stability, with the boys falling over easily, fitting can be complicated, and the period that the walking is prolonged can be a short one.

Swivel walkers were first introduced in America for children with amelia. The principle of their use is a pylon arrangement that uses side to side oscillation together with a forward centre of gravity to provide ambulation. Their use for children with a paraplegia was pioneered in the United Kingdom by Rose. ${ }^{3}$ Their use for patients with muscular dystrophy was first suggested in the United Kingdom in 1981, providing a means of low energy ambulation for the boys, and has been developed by Bennett. ${ }^{4}$ We describe our preliminary experience with swivel walkers in boys with Duchenne muscular dystrophy in schools for the physically handicapped in South Glamorgan.

\section{Methods and results}

Most of the boys with Duchenne muscular dystrophy at the special schools for the physically handicapped in South Glamorgan (Pentwyn and Erw'r Delyn) have actively chosen to use swivel walkers as part of a programme of physical treatment for their condition. This programme has been part of a multidisciplinary, problem orientated approach to muscle disease centred at the muscle clinic and regional genetic centre at the University Hospital of Wales (Professor P Harper and Dr J R Sibert). As well as dealing with the physical problems we offer a comprehensive genetic service and active help in resolving any problems in the home situation.

In 1984 swivel walkers were introduced into the special schools and up to now have been used by 11 boys. Only one boy had declined to participate because he felt unwilling to have the extra physiotherapy involved. We have used two types of swivel walkers: initially, we used the Shrewsbury type, but more recently we have had good experience with the Salford swivel walker. We have reason to believe that the Orlav swivel walker would also be satisfactory. Elective operations on the Achilles tendons have been performed in most boys to help wheelchair position and comfort and to help with the use of the swivel walkers.

The boys are placed in their swivel walkers by physiotherapists and helpers and are encouraged to walk. It takes two people about three minutes to place a boy in a walker. The boys can use their swivel walkers to go between classes or can be taken 
in a transporter. The distance travelled varies from 200 metres to a few metres. Our fastest patient takes about 10 minutes to travel 100 metres, but a more typical time is 20 minutes. Each boy has his own fitted swivel walker, which costs about $£ 600$. The parents are encouraged to take the apparatus home at weekends and during school holidays. All the boys who have started with these walkers are still using them, and some have had increased rather than deteriorating performance in them as measured by distance travelled and speed.

The morale of all the boys has increased using the swivel walkers. This has resulted in a greater interest in life and less depression. All the parents have been pleased with this method of treatment. One boy aged 16 restarted his $O$ level course after he had abandoned it. Only one boy has increased his weight centile since starting on the programme. One boy has developed scoliosis, for reasons unrelated to the swivel walker.

The mean age of the boys on beginning treatment with a wheelchair was 8.5 years and their mean intelligence quotient (IQ) was 85 . All the boys managed the swivel walkers, even the three with IQs below 70. In this series the mean age of the boys while on treatment with a swivel walker was 12.4 years, with a range of 9 to 15 years. We anticipate that these figures will decrease as boys enter the programme earlier.

\section{Discussion}

The advantage of prolonging mobilisation seems to be in preventing or reducing the inward looking attitude and depression that inevitably seems to affect boys with Duchenne muscular dystrophy. It will also help prevent obesity and may minimise deterioration in muscle power. The upright posture may also be helpful in preventing scoliosis. We have no doubt that swivel walkers are helpful to many boys with Duchenne muscular dystrophy. They do not, however, replace real walking and their use is limited to flat surfaces. They need a considerable amount of therapist time and close attention from the orthotist and the paediatrician.
Swivel walkers are difficult to fit if there are gross knee contractures and should probably be used when mobility is reduced before contractions develop. We believe that the prevention of scoliosis is important in muscular dystrophy. Scoliosis can be uncomfortable, limit upper limb function, and also be cosmetically unsatisfactory. Perhaps more importantly, it inevitably reduces lung function and probably reduces life span. We have used early jacketing to prevent scoliosis and we have been successful in all but one of our boys at special schools. The use of the Luque operation is an alternative approach to scoliosis in Duchenne muscular dystrophy.

So far we have mainly limited the use of swivel walkers to special schools for the physically handicapped in South Glamorgan. We have recently had some success with two boys, however, outside our county, one of whom attends a normal school. Both these boys have a dedicated physiotherapist and considerable parental support. Although the Warnock committee recommended that children with physical handicaps should be educated in local schools, we believe that in Duchenne muscular dystrophy there are often important advantages for boys who are educated in schools for the physically handicapped where they are able to take advantage together of a programme of physical treatment such as that outline in this paper.

\section{References}

' Spencer GE, Vignos PJ, Bracing for ambulation in childhood progressive muscular dystrophy. J Bone Joint Surg [Am] 1962;44:234-42.

2 Dubowitz V, Heckmatt J. Management of muscular dystrophy: pharmalogical and physical aspects. Br Med Bull 1980;36: $139-44$.

${ }^{3}$ Rose GK, Henshaw JT. A swivel walker for paraplegics: medical and technical considerations. Biomedical Engineering 1972;7:420-5.

4 Bennett P An effective physical regime for Duchenne muscular dystrophy children. Luton: Huntleigh Technology, 1984.

Correspondence to Dr J R Sibert, Department of Pacdiatrics, Llandough Hospital, Penarth, South Glamorgan CF6 1XX, Wales.

Received 28 November 1987. 